\title{
Factores bióticos y abióticos que deter minan la seroprevalencia de anticuerpos contra Trypanosoma Cruzi en el municipio de Palmar
de Bravo, Puebla, México
}

Francisca Sosa-Jurado, MSP, (1) José Lino Zumaquero-Ríos, MC, (2) Pedro A Reyes, Med, (3) A bel Cruz-García, MSP, ${ }^{(4)}$ Carmen Guzmán-Bracho, MC ${ }^{(5)}$ Víctor M Monteón, DC. ${ }^{(3)}$

\begin{abstract}
Sosa-J urado F, Zumaquero-Ríos]L, ReyesPA, Cruz-García A, Guzmán-Bracho C, Monteón VM. Factores bióticosy abióticos que determinan laseroprevalenciade anticuerposcontra Trypanosoma cruzi en el municipio de Palmar de Bravo, Puebla, México. Salud Publica Mex 2004;46:39-48.

El texto completo en inglés de este artículo está
\end{abstract} disponible en: http://www.insp.mx/salud/index.html

\section{Resumen}

Objetivo. D eterminar la prevalencia de anticuerpos contra Trypanosoma cruzi y su relación con los factores bióticos y abióticos en Palmar de Bravo, Puebla, México. Material y métodos. Estudio transversal efectuado en agosto de 2000 a septiembre de 2001, con una muestra aleatoria simple de 390 voluntarios residentes en Palmar de Bravo, Puebla, México. Se hizo determinación de anticuerpos contra T cruzi con técnicas seroló gicas validadas, búsqueda del vector y de reservorios domésticos, así como determinación de asociación entre caso positivo y factores de riesgo bióticos y abióticos. El análisis estadístico consistió en índice Kappa para las pruebas diagnósticas, empleando tabla de contingencia de $2 \times 2$; ji cuadrada corregida de Yates, exacta de Fisher y la razón de posibilidad para estimar la significancia de la asociación de factores bióticos y abióticos. Resultados La seroprevalencia fue de $4 \%$ en la población humana estudiada y de los reservorios (equinos, porcinos y caninos), sólo $10 \%$ de los caninos resultaron reactivos. Los vectores identificados fueron T barberi y T pallidipennis, con índice de dispersión e índice de colonización de 55 y 40\%, respectivamente. Los factores de
Sosa-J urado F, Zumaquero-RíosJL, ReyesPA, Cruz-García A, Guzmán-Bracho C, Monteón VM. Biotic and abiotic determinants

of ser oprevalence of antibodiesa gainst Trypanosoma cruzi

in Palmar de Bravo, Puebla, Mexico.

Salud Publica Mex 2004;46:39-48.

The English version of this paper

is available at: http://www.insp.mx/salud/index.html

\section{A bstract}

Objective.To establish the relationship between seroprevalence for antibodies against Trypanosoma cruzi and its relationship with biotic and abiotic factors. Material and Methods A cross-sectional study was conducted between August 2000 and September 2001. The study population consisted of a simple random sample of 390 volunteers residing in Palmar de Bravo, Puebla, Mexico. Sample and data collection procedures included assaying antibodies against $T$ cruzi with validated assays, and searching for domestic reservoirs and triatomine bugs. The relationship between biotic and abiotic factors with seropositivity was assessed. Statistical analysis was conducted using Kappa values for diagnostic tests; statistical significance was assessed with $2 \times 2$ tables, chi-squared test with Yates' correction, Fisher exact test, and odds ratios. Results The seroprevalence of T cruzi infection in humans was 4\%; in do mestic reservoirs (horses, pigs, and dogs) only 10\% of canine reservo irs were positive.Vector species recognized were T barberi and T pallidipennis, with a Dispersion Area Index and a C olonization Index of $55 \%$ and $40 \%$, respectively. The most important risk factors associated with positive serology were altitude

(1) Hospital de especialidades, Centro Médico N acional Manuel Avila Camacho. Instituto Mexicano del Seguro Social, Puebla, Puebla, México.

(2) Laboratorio de Entomología de la Escuela de Biología de la Benemérita Universidad Autónoma de Puebla, Puebla, México.

(3) Laboratorio de Inmunoparasitología del Instituto N acional de Cardiología, Dr Ignacio Chávez. México, DF, México.

(4) Facultad de Medicina de la Universidad Popular Autónoma del Estado de Puebla, Puebla, México.

(5) Departamento de Parasitología del Instituto N acional de Referencia Epidemiológica, México, D F, México.

Fecha de recibido: 10 de diciembre de 2002 - Fecha de aprobado: 4 de septiembre de 2003 Solicitud de sobretiros:Víctor M Monteón. Instituto N acional de Cardiología, Juan Badiano 1, colonia Sección XVI, 14080 México, DF. Correo electrónico: victormonteon@ hotmail.com 
riesgo más importantes fueron la altitud ( $>2150$ y $<2180$ metros sobre el nivel del mar), los años de residencia, el pertenecer a un programa de asistencia social, la presencia de triatóminos y la edad. Conclusiones. En localidades ubicadas a una altitud mayor a los 2000 metros sobre el nivel del mar se reconocieron vectores infectados con T cruzi, casos humanos y probablemente reservorios domésticos. El texto completo en inglés de este artículo está disponible en: http://www.insp.mx/salud/index.html

Palabras clave: Trypanosoma cruzi; enfermedad de Chagas; seroprevalencia; vectores; reservorios; México
(>2 150 y <2 180 meters above sea level), presence of triato mines, age, time of residence, and participation in a social assistance program. Conclusions T cruzi infection was identified in human beings, vectors, and possibly in domestic reservoirs, in communities located over 2000 meters above sea level.The English version of this paper is available at: http://www.insp.mx/salud/index.html

Key words: Trypanosoma cruzi; C hagas disease; seroprevalence; vectors; reservoirs; Mexico
$\mathrm{L}$ a tripanosomosis americana (TA) es una enfermedad causada por el protozoario flagelado Trypanosoma cruzi que se anida y reproduce en los tejidos. La infección es transmitida principalmente por los insectos hemípteros hematófagos (triatominos) a través de sus deyecciones contaminadas con tripanosomas metacíclicos. La enfermedad cursa con una fase aguda parasitémica, seguida por una fase crónica indeterminada asintomática y silente que puede durar toda la vida, o por una crónica sintomática en 30\% de los infectados. En esta fase crónica la parasitemia es difícil de demostrar y la serología es el recurso diagnóstico más importante. ${ }^{1}$

El parásito $T$ cruzi se ha detectado en humanos y en reservorios entre las latitudes $42^{\circ}$ norte a la $46^{\circ}$ sur del continente americano; la infestación de las viviendas por los vectores pone en riesgo de adquirir la infección a un mínimo de 90 millones de personas en el continente dentro de estas latitudes. ${ }^{2}$

La distribución de triatominos en México es muy amplia, se reconoce al vector en prácticamente todo el territorio y de las 31 especies reconocidas de Triatominae, la mayoría se han encontrado infectadas con $T$ cruzi, por lo que el riesgo de infección, en la población rural del país, se estima en 370000 individuos. ${ }^{3-5}$ Entre los animales domésticos el perro es el reservorio más importante de $T$ cruzi, $^{2}$ ya que se ha comprobado que los perros infectados incrementan el riesgo de la transmisión doméstica de $T$ cruzi. ${ }^{6}$

La infección por transfusión sanguínea es el segundo mecanismo de transmisión después de la vectorial, debido al incremento de la migración de personas de las zonas rurales endémicas a zonas urbanas donde no existen los triatominos, ${ }^{7-9}$ e incluso a zonas rurales no endémicas. De manera que la tripamosomosis americana (TA) es otra de las enfermedades sociales o de la pobreza, y en México se podría considerar como riesgo de salud emergente.

El diagnóstico serológico de la TA en su fase crónica es obligado, ya que es difícil la demostración del parásito en circulación o en los tejidos, por lo que es importante la estandarización de las pruebas serológicas para demostrar los anticuerpos contra T cruzi.

La Organización Panamericana de la Salud (OPS) recomienda que se utilice más de un procedimiento serológico para reducir el error en el diagnóstico. ${ }^{10} \mathrm{La}$ confirmación de un caso indeterminado de la tripanosomosis americana por diagnóstico serológico se establece cuando hay al menos dos pruebas serológicas positivas. $^{11}$

En México se han realizado varias encuestas seroepidemiológicas en población abierta y en donadores de sangre; en pocos casos se determinaron los factores de riesgo asociados a la prevalencia. ${ }^{12-14} \mathrm{El}$ estudio de la Encuesta Nacional de Seroepidemiología (ENSE) encontró relación de la prevalencia con algunos factores de riesgo como el tipo de vivienda, los años de radicar en zona endémica y la edad. ${ }^{15}$

En este trabajo se estudiaron la seroprevalencia humana, la probable presencia de reservorios domésticos y los factores de riesgo probablemente asociados en una población rural ubicada a más de 2000 metros sobre el nivel del mar (m snm). Para dar certeza del diagnóstico serológico se realizaron cuatro técnicas serológicas diferentes, en dos instituciones distintas, con una evaluación estadística de concordancia.

\section{Material y métodos}

\section{Población estudiada}

En el municipio de Palmar de Bravo, estado de Puebla, México, se estudiaron 15 localidades con una población en edad productiva de 15253 personas; las siete comunidades más pequeñas tenían una población total entre 100 a 500 habitantes, y las dos más pobladas entre 5000 y 7 500. (Datos del Instituto Nacional de Estadística, Geografía e Informática XII Censo General de Población y Vivienda 2000). 
Se logró la cooperación de 390 de los habitantes, a través de los médicos y auxiliares de salud de cuatro clínicas de la Secretaría de Salud (SSA) y una del Instituto Mexicano del Seguro Social (IMSS). Se reunió a las personas en las clínicas o en las casas de salud de cada localidad, entre los meses de agosto y septiembre de 2000, para informarles de la enfermedad de Chagas. Se emplearon medios audiovisuales, se les mostraron ejemplares de triatominos y se les explicó el objetivo del estudio, invitándolos a participar. A las personas voluntarias se les aplicó un cuestionario clínico-epidemiológico sobre datos personales, hábitos y costumbres, tipos de vivienda, manifestaciones clínicas y reconocimiento de los triatominos, y se les tomó una muestra de sangre y el suero se almacenó a $-20^{\circ} \mathrm{C}$, hasta su uso.

\section{Antígenos}

En el Instituto Nacional de Cardiología (INC) se empleó como antígeno epimastigotes de T cruzi cepa Ninoa; se obtuvieron extracto crudo soluble, para la realización de las técnicas de ELISA y WB (Ag-ECSINC), y una suspensión de parásitos para la inmunofluorescencia indirecta (IFI) (Ag-SP-INC). ${ }^{16}$

En el Instituto Nacional de Referencia Epidemiologica (INDRE) se empleó como antígeno epimastigotes de 15 aislamientos mexicanos (ocho de humanos y siete del vector); se obtuvieron extracto crudo soluble para el ensayo de ELISA (Ag-ECS-INDRE), una suspensión de parásitos para la IFI (Ag-SP-INDRE), y ECS con eritrocitos de pollo tratados con ácido tánico para hemaglutinación indirecta (HAI) Ag-(ECS-EP-INDRE). ${ }^{17}$

\section{Ensayos serológicos}

A las 390 muestras se les determinó anticuerpos contra T cruzi empleando como prueba tamiz la ELISA en el INC ${ }^{9,16}$ con dilución 1:200 del suero, conjugado anti IgG humano-peroxidasa 1:25 000 y tiempo de incubación de $15 \mathrm{~min}$ a $37^{\circ} \mathrm{C}$. El valor de corte se estableció con una muestra de 30 sueros de sujetos sanos, la media más 5DS nos permitió establecer el valor de corte de DO >0.240. En el INDRE la prueba tamiz fue la hemaglutinación indirecta HAI-INDRE ${ }^{18}$ que se considera positiva a diluciones $>1: 8$.

A los sueros positivos con alguna de las dos pruebas serólogicas empleadas se les determinó anticuerpos contra T cruzi con otras dos pruebas serológicas diferentes.
Por ELISA-INDRE ${ }^{17}$ a dilución de 1:50 del suero, conjugado anti IgG humano-peroxidasa 1:1 $000 \mathrm{y}$ tiempo de incubación de $1 \mathrm{~h}$ a $37^{\circ} \mathrm{C}$ con valor de corte DO $>0.220$, la obtención del valor de corte fue similar a lo descrito anteriormente; y por IFI-INDRE, ${ }_{1}^{17}$ con dilución de la muestra sérica 1:32 y conjugado anti IgG humano-fluoresceina 1:10 y tiempo de incubación de $30 \mathrm{~min}$ a $37^{\circ} \mathrm{C}$, se consideraron muestras positivas las diluciones $>$ 1:32.

La IFI-INC ${ }^{16}$ con dilución de la muestra sérica 1:32, conjugado anti IgG humano-fluoresceina 1:120, tiempo de incubación $30 \mathrm{~min}$ a temperatura ambiente, se consideró muestra positiva a diluciones $>1: 32$. El ensayo WBINC $^{9}$ en breve consistió en efectuar una electroforesis en gel $(10 \%)$ de SDS-poliacrilamida de las proteínas antigénicas que fueron transferidas a una membrana de nitrocelulosa y puestas en contacto con el suero diluido 1:1 000, e incubadas con el conjugado anti IgG humanoperoxidasa diluido $1: 2000$ durante $1 \mathrm{~h}$ a $22^{\circ} \mathrm{C}$ y, finalmente, la reacción enzimática se puso de manifiesto con 4-cloro-Naftol y $\mathrm{H}_{2} \mathrm{O}_{2}$. En todos los casos se corrieron de forma simultánea controles positivos y negativos.

\section{Búsqueda de vectores y de reservorios}

Se efectuaron tres campañas de captura de triatominos entre diciembre de 2000 y septiembre de 2001 en las cinco localidades donde se detectaron seropositivos, y se escogieron cuatro de las 10 donde no existió seroprevalencia. La captura fue manual, diurna, y se auxilió con guantes y lámparas de mano durante una hora/hombre/vivienda se buscaron chinches en cualquier estadio: huevo, ninfa y adulto. Los triatominos capturados se colocaron en un envase rotulado con el nombre de la localidad y del sitio de captura. Los triatominos capturados se identificaron y clasificaron con las claves de Lent y Wigodzinski. ${ }^{18}$

Para la búsqueda de hemoflagelados se obtuvieron heces por compresión del abdomen y se hizo observación en fresco además de tinción con Giemsa.

Durante la campaña de vacunación antirrábica efectuada en marzo de 2001, antes de ser vacunados y previo consentimiento de sus dueños, se tomó una muestra sanguínea a perros domésticos de las nueve comunidades anteriores; las muestras se identificaron según la localidad de origen de los animales y se efectuaron dos frotis de sangre que se tiñeron con Giemsa para la búsqueda de hemoflagelados, los sueros se almacenaron a $-20{ }^{\circ} \mathrm{C}$, hasta su uso. La determinación de anticuerpos séricos contra $T$ cruzi en perros se rea- 
lizó con la técnica de HAI-INDRE, ${ }^{17}$ y se consideraron positivas las diluciones $\geq 1: 16$.

\section{Estadística}

Obtención de indice de correlación de las pruebas serológicas

Para evaluar la eficacia de las pruebas tamiz como sensibilidad, especificidad, valor predictivo positivo y negativo e índice Kappa se empleó la tabla de contingencia $2 \times 2$ con los resultados emitidos, tanto por el INC y el INDRE.

\section{Análisis de datos e indices de correlación}

Los datos de las 390 encuestas, con 70 preguntas dicotómicas, fueron capturados en el programa Epi-Info 5 y se aplicó la prueba de ji cuadrada $\left(\chi^{2}\right)$ corregida de Yates y la exacta de Fisher, para determinar la significancia de las asociaciones observadas entre los factores bióticos y abióticos y los grupos de casos positivos y negativos, así como entre el grupo de individuos pertenecientes o no al programa de asistencia social y económica Progresa (Programa de Educación, Salud y Alimentación); el nivel de significancia se situó en $p<0.05$; las variables sometidas a este procedimiento estuvieron dentro de la escala nominal. Para obtener la probabilidad de ser caso positivo y donador de sangre se empleó la prueba de razón de posibilidad.

\section{Resultados}

\section{Pruebas diagnósticas}

$\mathrm{Al}$ considerar como caso positivo aquel individuo con al menos dos pruebas serológicas positivas encontramos 17/390 individuos seropositivos para una prevalencia de $4.35 \%$.

La eficacia de las pruebas serológicas tamiz HAIINDRE mostró sensibilidad de $82.3 \%$, y especificidad de $100 \%$, VP+ 100\% y VP- $99.35 \%$; la prueba tamiz ELISA-INC tuvo sensibilidad de $76.4 \%$, especificidad de $100 \%$, VP+ de $100 \%$ y VP- de $99.19 \%$. La concordancia entre las pruebas tamiz HAI-INDRE y ELISA-INC para detectar anticuerpos contra $T$ cruzi obtuvo un índice $\mathrm{K}=0.73$ (cuadro I).

Con HAI-INDRE 14 muestras fueron positivas y tres negativas, mientras que con ELISA-INC 13 fueron positivas y cuatro negativas. De las cuatro muestras negativas en ELISA-INC tres de ellas tuvieron valor de positividad límite en HAI-INDRE, con título de 1:8, y la otra de 1:32 (cuadro II). La concordancia entre las pruebas tamiz y las confirmatorias del INC (ELISA-
INC/IFI-INC) fue de índice $\mathrm{K}=0.86$, para una concordancia casi perfecta, ELISA-INC/WB-INC índice $\mathrm{K}=$ 0.78 , concordancia sustancial.

La concordancia entre la prueba tamiz y las confirmatorias del INDRE (HAI-INDRE / ELISA-INC) fue de índice $\mathrm{K}=0.89$, concordancia casi perfecta, HAIINDRE/ IFI-INDRE índice $\mathrm{K}=0.89$, concordancia casi perfecta.

La concordancia entre el INDRE y el INC fue de un índice $\mathrm{K}=0.82$, para una concordancia casi perfecta (cuadro I).

De las 17 muestras séricas positivas analizadas con IFI-INC se obtuvieron $15 / 17$ positivas, y con WB-INC se obtuvieron 11/17 positivas; con los resultados de las tres pruebas serológicas empleadas en el INC se detectaron 13 casos positivos para una prevalencia de $3.33 \%$. En el INDRE se obtuvieron $15 / 17$ positivas por ELISA-INDRE y con IFI-INDRE 17/17 positivas, los resultados de las tres pruebas serológicas empleadas detectaron a 16 casos positivos, para una prevalencia de $4.10 \%$ (cuadro II).

\section{Generales}

Se estudiaron 15 localidades del municipio de Palmar de Bravo, Puebla. Cinco estuvieron a una altitud de 2150 a $2180 \mathrm{~m}$ snm y 10 dispersas entre sí a una altitud de 2280 a $2500 \mathrm{~m} \mathrm{snm} .{ }^{19}$ De las 15 localidades estudiadas en cinco de ellas se detectaron casos serológicos positivos humanos.

La población estudiada tuvo las siguientes características: 390 voluntarios, en edad productiva ( 15 a 65 años), 366 (93.8\%) mujeres y 24 (6.2\%) hombres, edad promedio de 36.6 años, con promedio 41.7 de años de residencia. El 38\% campesinos, $56 \%$ dedicados a labores del hogar y temporalmente a labores del campo, $6 \%$ a otras actividades.

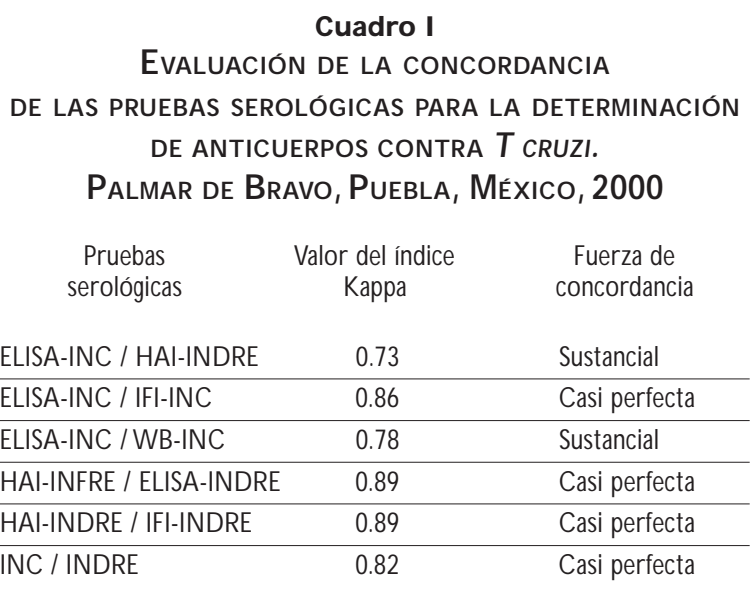




\section{Cuadro II \\ Resultados de La determinación de anticuerpos contra Trypanosoma CRUZI en encuestados LOS CUALES CON DOS PRUEBAS SEROLÓGICAS POSITIVAS RESULTARON SER CASO INDETERMINADO DE tripanosomosis americana. Palmar de Bravo, Puebla, México, 2000}

\begin{tabular}{|c|c|c|c|c|c|c|c|c|}
\hline \multirow[b]{2}{*}{ Folio } & \multicolumn{4}{|c|}{$\begin{array}{c}\text { Instituto Nacional de Cardiología } \\
\text { Dr Ignacio Chávez }\end{array}$} & \multicolumn{4}{|c|}{$\begin{array}{c}\text { Instituto de Referencia Epidemiológica } \\
\text { Dr M anuel Martínez Báez }\end{array}$} \\
\hline & $\begin{array}{c}\text { Prueba tamiz } \\
\text { ELISA } \\
\text { Dilución 1:200 } \\
\text { V.c. } 0.241\end{array}$ & $\begin{array}{c}|F| \\
\geq 1: 64\end{array}$ & Dilución 1:1 000 & $\begin{array}{c}\text { Caso } \\
\text { indeterminado }\end{array}$ & $\begin{array}{c}\text { Prueba tamiz } \\
\text { HAI } \\
\geq 1: 8\end{array}$ & $\begin{array}{c}\text { ELISA } \\
\text { Dilución } \\
1: 50 \\
\text { v.c. } 0.220\end{array}$ & $\begin{aligned} &|F| \\
& \geq 1: 32\end{aligned}$ & $\begin{array}{c}\text { Caso } \\
\text { indeterminado }\end{array}$ \\
\hline 008 & 0.103 & t+ & N & No & $1: 8$ & 0.267 & 1:128 & Sí \\
\hline 166 & 0.298 & + & $\mathrm{N}$ & Sí & $1: 128$ & 0.666 & $1: 128$ & Sí \\
\hline 213 & 0.817 & t+ & $P$ & Sí & $1: 64$ & 1.428 & $1: 128$ & Sí \\
\hline 218 & 1.702 & ++ & $P$ & Sí & $1: 1024$ & 2.676 & $1: 512$ & Sí \\
\hline 253 & 0.528 & + & $P$ & Sí & - & 0.205 & $1: 32$ & No \\
\hline 259 & 1.203 & t+ & $P$ & Sí & $1: 1024$ & 1.967 & $1: 1024$ & Sí \\
\hline 278 & 0.454 & + & $P$ & Sí & - & 0.350 & $1: 64$ & Sí \\
\hline 284 & 0.323 & + & $P$ & Sí & $1: 8$ & 0.700 & $1: 128$ & Sí \\
\hline 304 & 0.717 & + & $P$ & Sí & $1: 64$ & 1.609 & $1: 128$ & Sí \\
\hline 317 & 0.125 & - & $\mathrm{N}$ & No & $1: 8$ & 0.203 & $1: 32$ & Sí \\
\hline 318 & 0.193 & + & $\mathrm{N}$ & No & $1: 32$ & 0.364 & $1: 64$ & Sí \\
\hline 324 & 0.138 & + & $\mathrm{N}$ & No & $1: 8$ & 0.249 & $1: 128$ & Sí \\
\hline 326 & 0.402 & + & $P$ & Sí & $1: 64$ & 1.226 & $1: 128$ & Sí \\
\hline 353 & 0.358 & D & $P$ & Sí & $1: 32$ & 1.320 & $1: 128$ & Sí \\
\hline 363 & 0.463 & + & $P$ & Sí & $1: 32$ & 1.249 & $1: 128$ & Sí \\
\hline 379 & 0.424 & + & $P$ & Sí & - & 0.427 & $1: 128$ & Sí \\
\hline \multirow[t]{2}{*}{381} & 0.382 & +++ & $P$ & Sí & $1: 64$ & 1.132 & $1: 128$ & Sí \\
\hline & $13 / 390$ & $15 / 17$ & $12 / 17$ & $13 / 390$ & $14 / 390$ & $15 / 17$ & $17 / 17$ & $16 / 390$ \\
\hline revalencia & $3.33 \%$ & & & $3.33 \%$ & $3.58 \%$ & & & $3.84 \%$ \\
\hline
\end{tabular}

El 2\% habitó en viviendas con paredes de paja, madera o láminas de cartón, $12 \%$ en casas con paredes de adobe o piedra, $86 \%$ en casas con paredes de ladrillos; $62 \%$ en viviendas con techo de láminas de asbesto, metálicas o de tejas, $37 \%$ de concreto y $1 \%$ de paja; $20 \%$ habitó en viviendas con piso de tierra y $85 \%$ en viviendas sin servicio de drenaje. El $66 \%$ convivió con perros, gatos o ambos, $70 \%$ criaron principalmente cerdos, pollos o ambos, $87 \%$ refirieron la presencia de ratas y ratones en sus viviendas, y $12 \%$ avistaron tlacuaches y conejos silvestres merodeándolas. Ciento noventa y dos (49\%) pertenecieron al programa Progresa.

El 16\% reconoció a los triatominos. Ninguno refirió signo de Rómaña o chagoma de inoculación, no se identificaron enfermos. Aunque 5.8\% refirió dificultad para deglutir, $2.5 \%$ disnea o cansancio y $5.1 \%$ tuvo historial de donación de sangre. (Datos no mostrados).

\section{Vectores}

En las tres colectas efectuadas fueron revisadas $306 \mathrm{vi}-$ viendas y el entorno de las cinco comunidades con casos positivos humanos y cuatro comunidades en donde no se detectaron casos positivos humanos, en total nueve fueron las localidades analizadas para búsqueda de vectores y reservorios.

En las cinco comunidades en donde se detectaron casos positivos se obtuvieron los siguientes índices de infestación (cuadro II): para la localidad de Cuacnopalan, a 2180 m snm, 1.51\%, Palmar de Bravo, la cabecera municipal, a $2180 \mathrm{~m}$ snm 1.66\%, La Purísima, a 2180 m snm 3.83\%, Xaltepec, a 2150 m snm 1.66\% y Nazareno, a $2150 \mathrm{~m} \mathrm{snm}, 5.0 \%$. Las localidades donde no se detectaron casos positivos fueron: Bellavista, a 2280 m snm, Cuesta Blanca, a 2380 m snm, Tehuitzo, a 2380 m snm, y San Francisco Piletas, a 2400 m snm. 
El índice de dispersión del área (IDA) que comprendió a las nueve localidades donde se efectuaron capturas fue de $55.5 \%$, y el índice de colonización (IC) fue de $20 \%$. Se identificaron las especies $T$ barberi y $T$ pallidipennis y se obtuvo un índice de infección natural (IIN) de $10 \%$ en la especie $\mathrm{T}$ barberi (cuadro III).

\section{Reservorios}

Se determinaron anticuerpos contra $T$ cruzi por HAIINDRE a 94 muestras séricas de perros domésticos ( $\mathrm{Ca}$ nis familiaris), de raza indeterminada y aparentemente sanos. De ellas, 10 resultaron reactivas contra $T$ cruzi $(10.6 \%)$. Tres fueron a dilución baja de 1:16, cinco a dilución de 1:32 y sólo dos a 1:64. Las búsquedas de parásito circulante se realizaron en los frotis de sangre teñidos con Giemsa: todas resultaron negativas.

En humanos la dilución de corte es de 1:8; se consideró que para eliminar en lo posible reacciones cruzadas, que por lo general se observan a diluciones bajas, sólo muestras con títulos mayores o iguales a 1:16 serían positivos. De forma estricta, para establecer diagnóstico definitivo son necesarios los estudios parasitológicos como hemocultivo y/o xenodiagnóstico, pruebas que no pudieron llevarse a cabo por rechazo de los dueños.

\section{Factores determinantes}

Los factores bióticos o abióticos determinantes para ser caso positivo en este estudio fueron: a)habitar en localidades que están a una altitud entre los 2150 a $2180 \mathrm{~m}$ $\left.\operatorname{snm}\left(\chi^{2}=9.03 \operatorname{con} p=0.002\right) ; b\right)$ habitar en localidades donde se capturaron triatominos $\left(\chi^{2}=9.03 \operatorname{con} p=0.002\right)$; c) la edad $\left(\chi^{2}=46.25\right.$ con $\left.p=0.000\right)$, d)los años de radicar en su localidad ( $\chi^{2}=51.52$ con $p=0.000$ ); e) habitar en viviendas con paredes de paja, madera o láminas de cartón $\left(\chi^{2}=10.15\right.$ con $\left.p=0.013\right)$; f) el tener como actividad ocupacional campesino $\left(\chi^{2}=8.06 \operatorname{con} p=0.017\right)$; g) el criar cerdos de traspatio $\left(\chi^{2}=5.40 \operatorname{con} p=0.038\right)$, y h) el pertenecer al Progresa $\left(\chi^{2}=5.28\right.$ con $\left.p=0.009\right)$ (cuadro IV).

El $49 \%$ de los encuestados estuvieron integrados a Progresa; en este grupo se detectaron a 13/17 de los casos positivos para una prevalencia de $7 \%$. Mientras que en el restante $51 \%$, que no pertenecieron a este programa sólo se detectaron 4/17 para dar una prevalencia de $2 \%$. Al comparar a estos dos grupos originarios del mismo municipio y de ámbito rural y relacionar los factores bióticos y abióticos determinantes, obtuvimos lo siguiente: los encuestados del grupo del Progresa tienen mayor grado de hacinamiento $\left(\chi^{2}=36.60\right.$ con $p=0.0023$ ), habitan en las pocas viviendas construidas con materiales de paja, madera o láminas de cartón $\left(\chi^{2}=10.12\right.$ con $\left.p=0.001\right)$, un tercio de ellos habitan en vivienda con piso de tierra $\left(\chi^{2}=26.07 \operatorname{con} p=0.000\right)$, dos terceras partes conviven con más de un perro $\left(\chi^{2}=10.25\right.$ con $p=0.0013)$ y $92 \%$ refirieron la presencia de ratas y ratones en sus viviendas o en el entorno de éstas $\left(\chi^{2}=\right.$ 4.93. $\operatorname{con} p=0.026$ ) (cuadro V).

\section{Discusión}

El municipio de Palmar de Bravo es de ámbito rural, se encuentra ubicado cerca de la zona del Xitlaltepetl (Pico de Orizaba) en el estado de Puebla. En un estudio de estratificación estatal de la mortalidad en México, ${ }^{20}$ el estado de Puebla perteneció a la región de rezago extremo con una mortalidad infantil 1.9 veces más elevada que

\section{Cuadro III \\ INDICADORES ENTOMOLÓGICOS DE NUEVE LOCALIDADES ESTUDIADAS EN EL MUNICIPIO DE Palmar de Bravo, Puebla, México, 2000}

\begin{tabular}{|c|c|c|c|c|c|}
\hline Localidad & $\begin{array}{l}\text { Altitud } \\
\text { (m snm) }\end{array}$ & $\begin{array}{l}\text { Especie de } \\
\text { Triatominos } \\
\text { capturada }\end{array}$ & $\begin{array}{l}\text { Indice de } \\
\text { infestación } \\
\text { (II) }\end{array}$ & $\begin{array}{c}\text { Indice de } \\
\text { dispersión } \\
\text { del área (IDA) \% }\end{array}$ & $\begin{array}{c}\text { Indice de } \\
\text { colonización (IC) } \\
\%\end{array}$ \\
\hline Cuacnopalan & 2180 & T barberi & 1.51 & & \\
\hline La Purísima & 2180 & $\mathrm{~T}$ barberi & & & \\
\hline T pallidipennis & 3.84 & & & & \\
\hline Palmar de Bravo & 2180 & T barberi & 1.66 & & \\
\hline San Miguel X altepec & 2150 & T barberi & 1.62 & 55.5 & 40.0 \\
\hline Jesús N azareno & 2150 & T barberi & 5.00 & & \\
\hline Cuesta Blanca & 2380 & N inguna & 0.00 & & \\
\hline San José Bellavista & 2270 & N inguna & 0.00 & & \\
\hline Tehuitzo & 2380 & N inguna & 0.00 & & \\
\hline San Francisco Piletas & 2400 & Ninguna & 0.00 & & \\
\hline
\end{tabular}




\section{Cuadro IV \\ FACTORES Bióticos Y ABIÓtICOS DETERMINANTES PARA SER CASO DE TRYPANOSOMOSIS americana en el municipio de Palmar de Bravo, Puebla, México, 2000}

\begin{tabular}{lcc} 
Factor biótico o abiótico & Valor de $X^{2}$ & Valor de $p$ \\
$\begin{array}{l}\text { Habitar en localidades ubicadas } \\
\text { entre los } 2150 \text { a } 21800 \mathrm{~m} \text { snm }\end{array}$ & 9.03 & 0.0026 \\
\hline $\begin{array}{l}\text { Habitar en localidades donde se } \\
\text { capturaron triatominos }\end{array}$ & 9.03 & 0.0026 \\
\hline $\begin{array}{l}\text { La edad del encuestado } \\
\text { Años de radicar en la localidad } \\
\text { del encuestado }\end{array}$ & 46.25 & 0.0000 \\
\hline $\begin{array}{l}\text { Habitar en viviendas con paredes } \\
\text { de madera, palma o cartón }\end{array}$ & 51.52 & 0.0000 \\
\hline $\begin{array}{l}\text { Actividad ocupacional campesino } \\
\text { Criar cerdos de traspatio }\end{array}$ & 10.15 & 0.0013 \\
\hline $\begin{array}{l}\text { Pertenecer al Progresa* } \\
\text { m snm: metros sobre el nivel del mar }\end{array}$ \\
* Progresa: Programa de Educación, Salud y Alimentación
\end{tabular}

Cuadro V

ReLación de factores bióticos y abióticos QUe FUERON DETERMINANTES PARA UNA MAYOR PREVALENCIA De CASOS en LOS ENCUeSTAdos QUe PeRTeneCIeron aL Progresa, Palmar de Bravo, Puebla, México, 2000

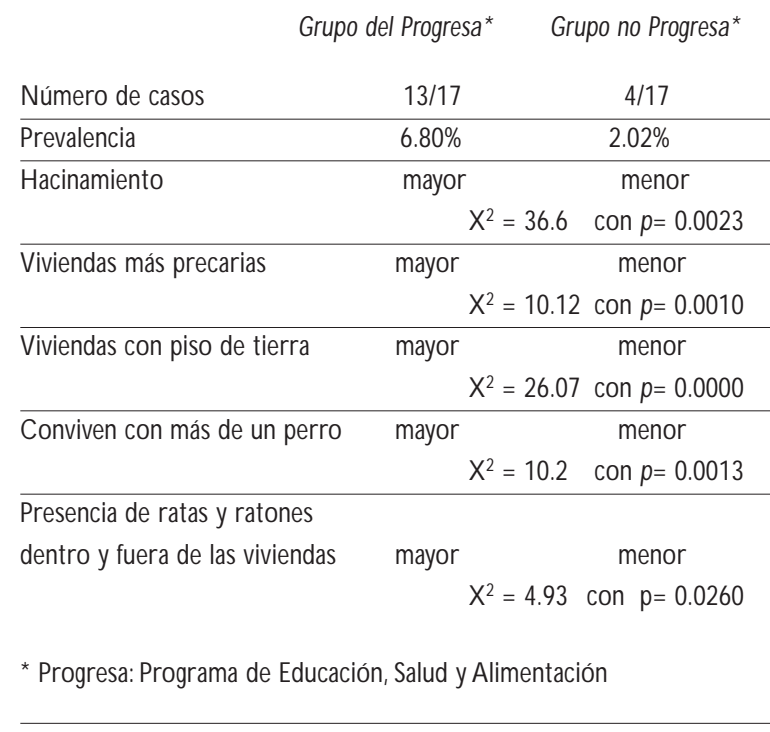

los estados que pertenecieron a la región de transición avanzada, y una mortalidad en los adultos arriba del promedio nacional. En este estudio, empleando el méto- do de Hanlon, ${ }^{21}$ encontramos que en los años de 1994 a 1998 los principales problemas de salud del municipio de Palmar de Bravo, Puebla, fueron la neumonía e influenza, las enfermedades infecciosas intestinales, las deficiencias de la nutrición en todos los grupos de edad, las afecciones en el periodo perinatal y los accidentes. En las zonas reconocidas como endémicas de la tripanosomosis americana se le ha detectado relacionada con las enfermedades llamadas sociales, y preferentemente dentro del ámbito rural. ${ }^{1}$ En el anterior contexto realizamos la determinación de la relación de la prevalencia de anticuerpos contra T cruzi y los factores de riesgo bióticos y abióticos del medio ambiente estudiado.

En las encuestas seroepidemiológicas hechas en población abierta en México sobre la tripanosomosis americana, que se han efectuado en zonas endémicas y no endémicas, la toma de muestra, tipos de muestreo, grupos etáreos, pruebas serológicas y antígenos (cepas de $T$ cruzi) han sido heterogéneos. En consecuencia, estas variables pueden tener efecto sobre los valores de seroprevalencia. ${ }^{12-14}$ Sólo dos encuestas realizadas, una en el estado de Jalisco ${ }^{22}$ y la Encuesta Nacional de Seroepidemiología (ENSE) consideraron los datos oficiales de población de las localidades o de los estados estudiados. La ENSE fue diseñada para detectar prevalencias nacionales, regionales y estatales de enfermedades con impacto en la salud pública de México; probablemente excluyó a localidades rurales de difícil acceso; salvo lo anterior, es representativa de la realidad nacional. ${ }^{15}$

El estudio actual utilizó un muestreo aleatorio simple, considerando en el diseño del tamaño de muestra la población censada en edad productiva en el municipio de Palmar de Bravo.

Otro factor que se ha observado influye de forma marginal en el valor de la seroprevalencia es el tipo de antígeno empleado para detectar anticuerpos contra T cruzi en una zona determinada. ${ }^{14}$ En este estudio se utilizaron dos antígenos diferentes y cuatro pruebas serológicas para el análisis de 390 muestras séricas. A todas estas se les detectaron, primero, anticuerpos contra $T$ cruzi con las pruebas tamiz ELISA-INC y HAIINDRE. La eficiencia de estas pruebas: sensibilidad, especificidad, VP+ y VP- estuvieron dentro de un rango aceptable, con un índice de correlación $\mathrm{K}$ de 0.73 ; se obtuvo una concordancia sustancial entre ellas ya que coincidieron en 10 muestras; cuatro de las muestras negativas en ELISA-INC, y positivas por la prueba tamiz HAI-INDRE, resultaron apenas positivas a diluciones de 1:8 en tres de los casos y sólo una dio positiva a 1:32. Las tres muestras que resultaron negativas por la prueba tamiz HAI-INDRE se ubicaron por ELISA-INC cercanas al valor de corte (cuadro II). 
Los resultados obtenidos con las pruebas tamiz indicarían que la detección de casos con títulos muy bajos de anticuerpos y cercanos al límite de la prueba es un problema, ya que al ajustarlas a alta sensibilidad se incrementa el riesgo de falsos positivos, como al parecer es el caso, pues las muestras discordantes se ubicaron a diluciones bajas o a valores cercanos al límite de detección de las pruebas.

La concordancia entre la prueba serológica y las confirmatorias tamiz entre los dos institutos fue casi perfecta con un índice $\mathrm{K} 0.82$, resultado que confirma un estudio previo entre ambos institutos, llevado a cabo con sueros de pacientes crónicos, donde la concordancia fue de $\mathrm{K} 0.83 .{ }^{23}$ Los casos positivos así obtenidos tienen un alto grado de confiabilidad.

Las diferencias observadas pudieran deberse, entre otras causas, al método de preparación del antígeno que puede enriquecer algún componente inmunodominante no identificado, aunque esta variable pareciera no ser uno de los factores más importantes, ya que en los casos se utilizó tan sólo el extracto antigénico, proveniente de una cepa de T cruzi, y otro en donde se utilizaron las mezclas de 15 cepas; en ambos existieron muestras no reconocidas por uno y otro extracto. Vale la pena resaltar que las muestras estudiadas en este trabajo provienen de individuos que viven en zonas de baja endemia para la infección y, en consecuencia, los títulos de anticuerpos específicos suelen ser más bajos que los de individuos que se encuentran en zonas de alta transmisión.* La mayoría de las encuestas seroepidemiológicas publicadas en México sobre la tripanosomosis americana han sido realizadas en localidades que están a menos de $2000 \mathrm{~m} \mathrm{snm} .^{24}$

En este estudio se obtuvo una prevalencia de casos positivos de $7 \%$ entre 244 voluntarios habitantes de cinco localidades a una altitud entre los 2150 a $2180 \mathrm{~m}$ snm, con una temperatura promedio anual de $18{ }^{\circ} \mathrm{C}$; además, en estas áreas se capturaron triatominos . Mientras que entre los 146 voluntarios de 10 localidades pequeñas y dispersas entre sí, las cuales estuvieron a una altitud entre los 2280 a $2500 \mathrm{~m} \mathrm{snm}$, con una temperatura promedio anual $14^{\circ} \mathrm{C}$, no hubo casos positivos ni se capturaron triatominos.

En otro estudio en una localidad rural de Puebla, localizada a una altitud de $1800 \mathrm{~m}$ snm y con temperatura promedio de $22^{\circ} \mathrm{C}$, la prevalencia contra $T$ cruzi fue de $10 \% .{ }^{14}$ Estas observaciones dan apoyo al concepto de que la altitud y el clima son factores importantes para la existencia del vector y el riesgo de infección por T cruzi en humanos y reservorios.

\footnotetext{
* Monteón et al. Artículo en preparación
}

Los indicadores entomológicos obtenidos en este trabajo pueden tener sesgo por factores culturales de la población, debido a que en las capturas no todos los residentes permitieron buscar al vector en sus viviendas. No obstante, las especies de triatominos reconocidas en este estudio fueron T barberi, capturado en cinco localidades, y T pallidipennis, capturado en una localidad. Además, se colectaron ninfas y huevecillos de $T$ barberi que indicaban colonización reciente e índice de infestación natural con $T$ barberi, lo que supone transmisión vectorial de T cruzi a humanos y reservorios. En México la presencia de los triatominos ha sido reconocida en todo el país preferentemente por debajo de los $2000 \mathrm{~m} \mathrm{snm}^{24}$ pero el T barberi es capaz de vivir en zonas elevadas de clima templado a frío siendo uno de los principales vectores de importancia epidemiológica en México. ${ }^{3}$

Habitar en viviendas con paredes de paja, láminas de cartón o madera fue un factor abiótico determinante para ser caso positivo con una RM de 1:6, asociación similar a la encontrada en la ENSE que a escala nacional tuvo una RM de 1:3. ${ }^{15}$

Los años de radicar en el municipio fueron un factor abiótico determinante directo: a más años de residencia mayor riesgo. Puede ser que exista mayor oportunidad de reinfección al residir en localidades donde existen triatominos y animales infectados con T cruzi.

El grupo etáreo de los voluntarios fue un factor biótico determinante para ser caso positivo; la seroprevalencia aumentó con la edad; en el rango de 15 a 25 años la prevalencia fue de $2.1 \%$, y aumentó entre la tercera y cuarta década, cerca de $7 \%$, observación que coincide con los hallazgos en la ENSE. ${ }^{15}$ La edad promedio de nuestros casos positivos fue de 41.4 años $y$ los mayores de 36 años reconocieron a los ejemplares de triatominos.

La TA está presente en poblaciones humanas del medio rural. ${ }^{2}$ En este estudio el ser campesino fue otro factor abiótico determinante para ser caso positivo con un RM de 1:4, tal vez porque estas personas están, además, expuestas a los triatominos silvestres.

El Progresa atiende población en pobreza extrema. El estar integrado a éste fue un factor abiótico determinante con un RM de 1:4. Se detectaron en el grupo Progresa a 13/17 casos positivos; este grupo de población se distingue de los restantes (51\%) voluntarios también, pobladores de este municipio de ámbito rural, porque sus viviendas son las más precarias, conviven en forma directa con un reservorio importante de T cruzi como son los perros ${ }^{6}$ e indirectamente con ratas y ratones..$^{25}$ Además, observamos que el tamaño de los terrenos en los que habitan las familias integradas al Progresa no son de tamaño suficiente para albergar 
a la vez vivienda, corrales de animales y almacenar paja o leña en el patio; estos terrenos están juntos unos de otros formando manzanas en localidades que además carecen de servicios públicos.

Los perros domésticos han sido implicados como el segundo reservorio más importante de T cruzi, y son muy relevantes en el ciclo doméstico por su fuerza de infectividad. ${ }^{6}$ En este trabajo, de 94 perros domésticos analizados $10.6 \%$ fueron serorreactivos a $T$ cruzi, cohabitaron en las localidades donde también hubo casos humanos positivos y triatominos. En este estudio los perros resultaron ser reservorios domésticos importantes $(p=0.0013)$.

La infección por T cruzi la pudieron haber adquirido, ya sea por ingestión de insectos o roedores infectados, puesto que duermen en pajares y su fuente de proteína son tuzas y ratones de campo.

Los estudios con perros como el segundo reservorio más importante de $T$ cruzi ha sido reconocido ampliamente en Argentina. ${ }^{6,26}$

En México, por lo tanto, los perros también pudieran ser considerados como un probable reservorio dentro del ciclo doméstico de la TA, por lo cual debiera investigarse esta posibilidad más ampliamente.

La razón de probabilidad de ser caso positivo fue de 1:20, la de tener historial de donación de 1:25 y la razón de probabilidad de que estas dos características se den en un solo individuo fue de 1:11. Datos importantes, ya que los individuos seropositivos asintomáticos son los responsables de la urbanización de la TA donde no existen vectores

En este estudio demostramos que en el municipio de Palmar de Bravo, Puebla, del ámbito rural, y ubicado a más de $2000 \mathrm{~m} \mathrm{snm}$, existen humanos seropositi$\operatorname{vos}(4 \%)$, un probable reservorio doméstico, los perros de los que $10.6 \%$ fueron reactivos a anticuerpos contra T cruzi. Se encontró, además, la presencia de vectores como $T$ barberi y $T$ pallidipenis. Los factores de riesgo más importantes fueron la presencia de triatominos, la altitud (no mayor a los $2200 \mathrm{~m} \mathrm{snm}$ ), la pobreza extrema, habitación precaria, y la convivencia con reservorios. Los restantes factores que resultaron también determinantes para ser caso positivo, por lo general son comunes al ámbito rural del país.

El empleo de varias técnicas serológicas asegura la confiabilidad de los resultados, y los extractos antigénicos utilizados, ya sea provenientes de una cepa o varias, parecen no influir el resultado final; sin embargo, será necesario ampliar este tipo de estudios con una muestra de sujetos indeterminados, y así verificar estos hallazgos iniciales, que sugieren que la cepa de $T$ cruzi influye de forma sólo marginal en el resultado. ${ }^{27}$

\section{Agradecimientos}

Dra Manuela Vázquez de la Unidad de Salud de Cuesta Blanca, Dr Delfino Díaz Jiménez de Palmar de Bravo, Dr Jesús Ortiz Castro de Cuacnopalan y MPS Armando Velásquez Merino de San Miguel Xaltepec y a los auxiliares de salud de cada una de estas unidades por su colaboración en reunir a los pobladores y en la toma de muestras. Así como al Lic Pedro Barojas de Rosas, presidente municipal de Palmar de Bravo en 2000, al Dr Jesús Salazar Alba, síndico municipal y a la Sra Patricia Simón, auxiliar de salud de la localidad de Nazareno por su colaboración en las colectas de triatominos, y muestreo a perros. A la bióloga Ma Concepción Moreno Zenteno por su amplia colaboración en este estudio.

\section{Referencias}

1. Acha P, Szyfres-Boris. Zoonosis y enfermedades transmisibles al hombre y a los animales: enfermedad de Chagas.W ashington, DC: O PS/ O MS, 1992: 590-601.

2. Pinto-Días JC,W endel S, Brener Z, Camargo ME, Rassi A. Epidemiology of Chagas disease. Sao Paulo: Ed ISBT, 1992:1-5.

3. Guzmán-Bracho C. Epidemiology of Chagas disease in México:An update.Trends Parasitol 2001;17:372-376.

4.Zárate LG, Zárate RA. C hecklist of the Traiatominae (Hemiptera:Reduviidae) of Mexico. Int J Entomol 1985;27:102-127.

5. Vidal-A costa V, Ibáñez-Bernal S, Martínez-C ampos C. Infección natural de chinches Tratominae con Trypanosoma cruzi asociadas a la vivienda humana en México. Salud Publica Mex 2000; 42(6):496-503.

6. Gurtler RE, Céceres MC, Rubel DN, Petersen RM, Schweigman N I, Lauricella $\mathrm{Ma}$ et al . Chagas disease in north-west Argentina: Infected dogs as a risk factor for the domestic transmission of Trypanosoma cruzi. Trans R Soc Trop Med Hyg 1991; 85:741-745.

7. W endel S, Brener Z, Camargo ME, Rassi A. C hagas disease (American trypanosomiasis): Its impact on transfusion and clinical medicine. Sao Paulo, Ed. ISBT; 1992:1-3.

8. Guzmán-Bracho C, García-García L, Florián-Verdugo J, G uerreroMartínez S,Torres-Cosme M, Ramírez-Melgarejo et al. Riesgos de transmisión de T cruzi por transfusión de sangre. Rev Panam Salud Publica 1998; 4(2):590-601.

9. Monteón-PadillaVM, Hernández-Becerril N , G uzmán-Bracho C, Rosales-Encinas JL, Reyes-López PA. A merican tripanosomiasis (C hagas disease) and blood banking in Mexico City: Seroprevalence and its potential transfusional transmission risk. Arch Med Res 1999; 30:393-398.

10. Camargo ME, Segura EL, Kagan IG, Pacheco-Souza JM, C arvalheiro JR,Yanovsky JF. N ormalización del diagnóstico serológico de la enfermedad de Chagas en Las A méricas: evaluación de tres años de colaboración. Bol 0 ficina Sanit Panam 1987;102(5):449-463. 11. Secretaria de Salud. PROY-N O M-032-SSA2-2000. Para la vigilancia, prevención y control de enfermedades transmitidas por vector. México DF: Diario 0 ficial de la Federación, 21 N ov 2000. 2a sección. 12. Salazar-Schettino PM,Tay ZJ, Ruiz-Hernández AL, D e Haro Cl, Jiménez J, García-Yáñez Y et al. Seropositividad a Trypanosoma cruzi en 
cuatro grupos de población del estado de 0 axaca. Salud Publica Mex 1984; 26(6):589-595.

13. Ruegger-Gutiérrez L, Monteón-Padilla VM, Marcuschamer J, ReyesLópez PA.Tripanosomiasis americana (enfermedad de Chagas) encuesta clínico-serológica en un municipio rural oaxaqueño. Arch Inst $\mathrm{Cardio}$ Mex 1993; 63:341-346.

14. Pérez-Fuentes $R$, Sánchez-G uillén MC, G onzález-Alvarez $C$, Monteón-PadillaVM, Reyes-López PA, Rosales-Encinas JL. Humoral nitric oxide levels and antibody immune response of symptomatic an indeterminate $C$ hagas disease patients to commercial and autochthonous Trypanosoma cruzi antigen. Am Soc Trop Med Hyg 1998; 58(6):715 - 720.

15. Velasco-C astrejón 0 ,Valdespino JL,Tapia-C onyer R, Salvatierra B, Guzmán-Bracho MC, Magos C et al. Seroepidemiología de la enfermedad de Chagas en México. Salud Publica Mex 1991; 34(2):186-196.

16. Monteón-PadillaVM, SosaT, Reyes-López PA. Serological test for American trypanosomiasis: A comparative study. Rev Lat Microbiol Mex 1989; 31:35-38

17. Guzmán BC, Floriani VJ, Guerrero MS, Ramírez N A, Hernández MG Cuauhtécatl HA. Manual de procedimientos de laboratorio del InDRE: diagnóstico de laboratorio de la enfermedad de Chagas. México, DF: InD RE, SSA, 1999:19-37.

18. Lent $\mathrm{H}, \mathrm{W}$ igodzinsky P. Revision of the triatominae (Hemiptera: Reduviidae), and their significance as vector of $\mathrm{C}$ hagas disease. Bull Am Mus N at Hist 1979; 163:124-520.

19. Sistema Estatal de Protección Civil, Instituto N acional de Estadística, Geografía e Informática. Información N omenclátor para el estado de
Puebla. Localidades, instalaciones diversas, orografía, hidrografía y formas costeras y marítimas. México, DF: IN EGI,1995.

20. Frenk MJ, Lozano R. 0 bservatorio de la salud: necesidades, servicios y políticas. México DF; Ed Fundación México para la Salud, 1997:28-31. 21. Pineault $R, D$ aveluy $C$. La planificación sanitaria: conceptos, métodos, estrategias. 2a ed. Madrid: Masson, 1994:236-239. 22. Velasco-C astrejón 0, Ramírez J, Sánchez B,Trujillo F, Guzmán BC . La enfermedad de Chagas en Jalisco, México. Rev Mex Parasitol 1989;2:29-32. 23. Monteón PVM, Guzmán BC, Floriani VJ, Ramos EA,Velasco CO, Reyes LPA. Diagnóstico serológico de la enfermedad de Chagas: autosuficiencia y concordancia interlaboratorios. Salud Publica Mex 1995; 37(3): 232-235.

24. Vallejo AM, Reyes-López PA. LaTrypanosomosis americana ¿Un problema socio médico en México? Arch Inst Cardiol Mex 1996; 66:95-97.

25. Solís-Franco RR, Romo-Zapata JA, Martínez-Ibarra A.W ild reservoirs infected by Trypanosoma cruzi in the Ecological Park "El Zapotal" Tuxtla Gutiérrez, Chiapas, México. Mem Inst 0 swaldo C ruz 1997; 92(2):163-164.

26. Gurtler RE, Petersen RM, Lauricella MA,W isnivesky-C olli C. Infectivity to the vector Triatoma infestans of dogs infected with Trypanosoma cruzi in north-west Argentina. Ann Trop Med Parasitol 1992; 86(2):111-119.

27. Monteón-PadillaVM, Ramos EA, Reyes-López PA. Reactividad de sueros de pacientes chagásicos crónicos con extractos de aislamientos mexicanos de Trypanosoma cruzi. Rev Biol Trop 1993; 41(3):861-865. 